\title{
Making sense of the link between tiller density and pasture production
}

\author{
C. MATTHEW, A. HERNANDEZ-GARAY and J. HODGSON \\ Department of Plant Science, Massey University, Private Bag 11-222, Palmerston North, New Zealand
}

\begin{abstract}
Interpretation of tiller or shoot density data requires resolution of two independent, confounding effects, namely size/density compensation and what is here called the "leaf area effect". Size/density compensation implies that at higher herbage mass, individual tillers or shoots are larger, but the population density is correspondingly decreased. The leaf area effect represents difference in sward leaf area for two tiller populations. Such leaf area differences may be environmentally or genetically determined, but must of necessity be expressed through change in tiller size and/or tiller density as "yield components" of leaf area. The theoretical basis for distinguishing between size/density compensation and the leaf area effect is to consider tiller or shoot density and herbage yield, respectively, as $\mathrm{X}, \mathrm{Y}$ co-ordinates in a size/density plot. When such a plot is drawn on a logarithmic scale, points along a line of $-1 / 2$ slope show size/ density compensation with respect to each other. Movement of points to the right or left of the size/ density compensation line is evidence of a leaf area effect. It is shown that when the size/density effects are removed from a data set in this way, rankings of experimental treatments for the leaf area effect can often be reversed compared with the ranking of uncorrected tiller density. Tiller density data corrected for size/density compen-. sation in this way appear to be a useful indicator of sward productivity.
\end{abstract}

Keywords: sizeldensity compensation, sward productivity, tiller density

\section{Introduction}

Tiller density measurement has been used worldwide for many years as an indicator of agronomic status of swards in forage studies. The individual shoot or tiller is a convenient unit of study, even though it is recognised that a sward is a heterogeneous collection If tillers at different growth stages (Davies 1977). In iddition, it is recognised that different hierarchical levels of aggregation may operate simultaneously within a sward (Brock \& Hay 1993). Thus, there is no universal interpretation of tiller density data. On the question of the relationship between tiller density and herbage yield, one earlier reviewer (Langer 1963) concluded that in some conditions tiller density can be used as an index of yield, whereas in others tiller weight is more important.

This paper seeks to develop a consistent link between tiller density and herbage production, in order to increase the interpretive power of tiller density measurement as an agronomic indicator. Our thesis is that tiller density may be used as a measure of sward productivity if one first corrects for fluctuation in tiller population arising from size/density compensation. In layman's terms, closely grazed sheep pastures may have a tiller density of 20000 tillers $/ \mathrm{m}^{2}$, whereas more laxly grazed dairy pastures may have a tiller density of only 5000 tillers $/ \mathrm{m}^{2}$. No one would expect the sheep pasture to be four times as productive as the dairy pasture. The reason is that the average weight of a tiller in the sheep pasture may be as low as $13 \mathrm{mg}$, whereas the average weight of a tiller in the dairy pasture may be as much as $100 \mathrm{mg}$. This is size/density compensation.

\section{Theoretical considerations}

\section{Size/density compensation}

The inverse relationship between tiller size and tiller density has long been recognised. Langer (1963) noted several references to the phenomenon. The relationship was formalised by Yoda et al. (1 963) who showed that logarithmic plots of shoot weight against shoot density for various plant species commonly assume a $-3 / 2$ slope. The rule can also be formulated in terms of a relationship between herbage mass and shoot density. In this case logarithmic plots of herbage mass against shoot density have a $-1 / 2$ slope (Weller 1987 ). The rule was found to be widely applicable and was even hailed as the first law of plant ecology (Hutchings 1983). A number of authors, including Bircham \& Hodgson (1983), Davies (1988), and Chapman \& Lemaire (1993) have applied the rule to grass swards. Some recent authors have severely questioned the rule (Ldnsdale 1990), but a re-evaluation of the rule (Sackville Hamilton et al. 1995) and investigation of the application to forage plants (Matthew et al. 1995a) 
have shown that there is indeed an underlying $-\mathbf{3} / 2$ size/density compensation slope. Matthew et al. (1995a) proposed that tiller size/density combinations which lie along a common $-3 / 2$ slope on a logarithmic plot (or pasture cover/tiller density combinations lying along a $-1 / 2$ slope) show size/density compensation. This compensation line can be conceptualised as defining a line of constant leaf area index (Sackville Hamilton et al. 1995).

\section{Leaf area effect}

It follows from the above, that movement of either the tiller size or tiller density status of a sward, without compensatory change in the other and assuming no change in leaf:non leaf ratio, alters sward leaf area index. Swards which are plotted to the right of (i.e., above) a size/density compensation line will have a higher, and swards to the left (below) a lower leaf area index, respectively. Such movement to the right or left of a tiller size/density compensation line can conveniently be measured as a vertical shift on the Yaxis and is proposed by Matthew et al. (1995a) as an

Figure 1 Three formulations of tiller size/density plot. Data are from perennial ryegrass swards at Palmerston North. (a) Scatter plot of untransformed data, (b) Log biomass:log tiller density plot to illustrate Weller's (1987) - 1/2 formulation of the size/density rule, (c) Log tiller size:log tiller density plot illustrating the -312 formulation of the rule. Solid lines in Figures $1 \mathrm{~b}$ and $\mathrm{lc}$ represent the theoretical $-1 / 2$ and $-3 / 2$ slopes, respectively, conceptualised as a constant productivity line. Dotted lines show the "leaf area effect" whereby tiller density successively falls away from the compensation line at lower tiller size, due to effect of defoliation pressure in reducing sward leaf area index.

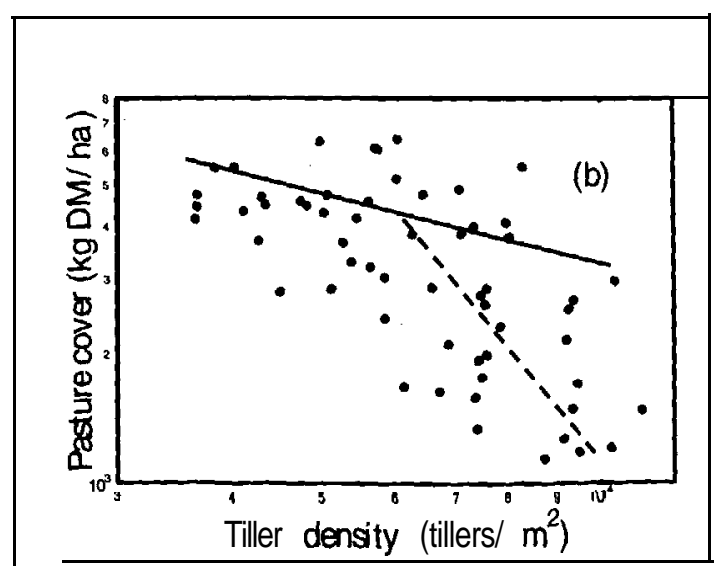

index of sward productivity. Figures la, $1 \mathrm{~b}$ and lc show three different presentations of size/density compensation data for perennial ryegrass swards at Palmerston North. A scatter plot (Figure la) suggests linear size/density compensation (Each $100 \mathrm{~kg}$ DM/ha increase in herbage mass associated with a decrease in tiller density of 210 tillers $/ \mathrm{m}^{*}, \mathrm{R}^{2}=0.41, \mathrm{P}<0.001$ ). The logarithmic herbage mass/tiller density formulation (Figure 1 b) shows slope near the theoretical value of $1 / 2$ at high herbage mass (solid line), but steeper slope at lower herbage mass (dotted line). This biphasic pattern of size/density compensation is seen even more clearly (Figure lc) when data are plotted as $\log ($ tiller size) versus $\log$ (tiller density), as required for the $-3 / 2$ formulation of the rule. Figure ic confirms the conclusion from Figure $1 \mathrm{~b}$, that swards under more intensive grazing pressure and maintained at lower average herbage mass fall away from the compensation line at a size/density slopes greater than the theoretical values of $-1 / 2$ (logarithmic plot of herbage mass versus tiller density) or $-3 / 2$ (logarithmic plot of tiller size versus tiller density, dotted lines, Figures 1 b, 1 c).
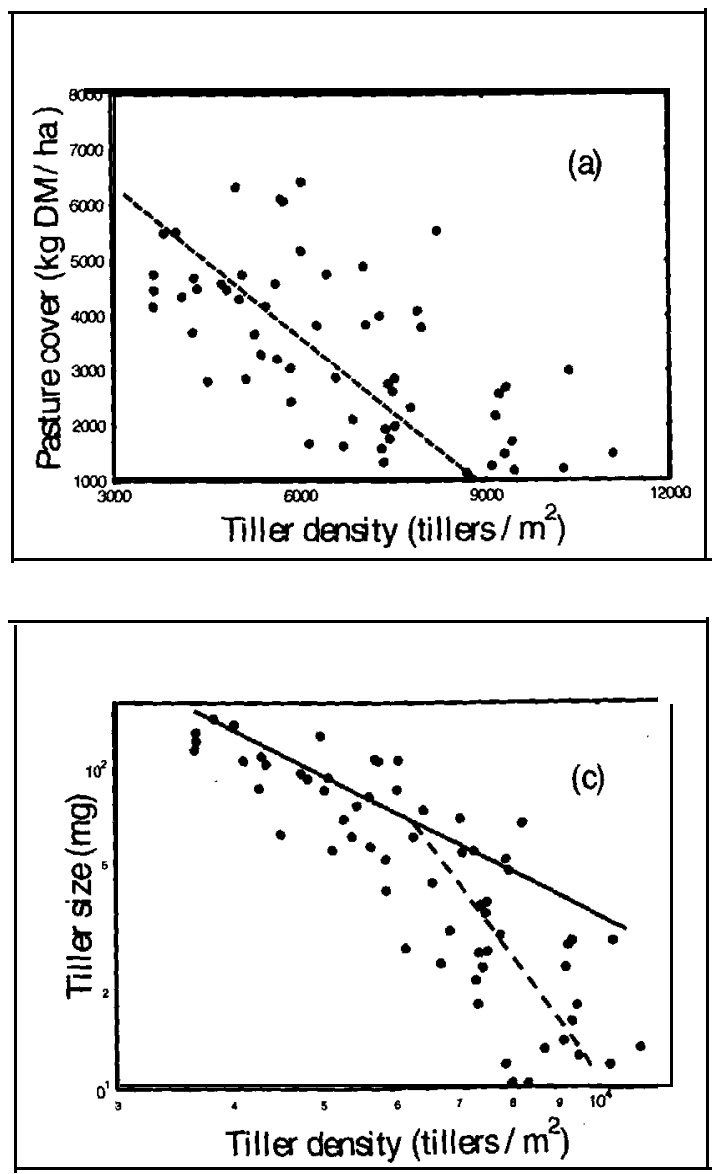


\section{Applications}

The above theory may be applied at either a general level, or to provide quantitative adjustments for specific measurements. At the general level, movement of tiller size/density co-ordinates down the steeper arm of Figure $1 \mathrm{~b}$ or Figure $1 \mathrm{c}$ (as in more intensive grazing regimes) implies loss of productivity. This occurs because tiller density increase achieved in moving down the slope is less than that required to maintain the sward leaf area at the previous value. On this basis, recommendation (Anon. 1991; Brock \& Hay 1993) of grazing policies which increase tiller density through lower levels of average herbage mass is to be avoided. Moreover, increased clover contents reported in such swards (Anon. 1991; Brock \& Hay 1993) can be explained as occupancy by clover of the canopy leaf area represented by the wedge below the compensation line but above the steeper dotted line (Figures 1 b 1 c).

The point at which sward leaf area begins to fall away from the compensation line is of interest. Matthew et al. (I 995a) proposed that it might be useful as an indicator of mature tiller size for a species or cultivar. Also herbage accumulation rate should increase with increasing herbage mass until a sward reaches this point. For ryegrass swards at Palmerston North this point ,was located (Matthew et al. 1995a) on the conipensation line at $\log$ (density) values of 3.5 and 3.9 in November and May, respectively, with the compensation line shifting seasonally about $0.17 \log$ units on the $\mathrm{Y}$-axis, presumably due to change in light levels. While small changes in such $\log$ values would give large changes in predictions for sward mass, these values correspond approximately to a pasture mass range of $5200 \mathrm{~kg} \mathrm{DM} / \mathrm{ha}$ in late spring to $2200 \mathrm{~kg} \mathrm{DM} /$ ha in late autumn. Other analyses (Matthew et al. 1995b) also support the conclusion that productivity is optimised at herbage mass between 2000 and $3000 \mathrm{~kg}$ $\mathrm{DM} /$ ha in swards in winter. Brougham (1956) cited lower herbage mass values around $1000 \mathrm{~kg} \mathrm{DM} / \mathrm{ha}$ for maximum herbage accumulation in winter but these values are probably also comparable since they exclude herbage below a cutting height of $25 \mathrm{~mm}$. The finding by Bircham \& Hodgson (1983) of optimum pasture productivity in British swards at lower herbage mass levels near $1300 \mathrm{~kg} \mathrm{DM} / \mathrm{ha}$ is consistent with leaf area for British swards not beginning to fall away from the compensation line until $\log ($ density) $=4.3$ (Matthew et al. 1995a).

Data from swards maintained at a range of cutting heights under more controlled conditions in a glasshouse at Massey University (Table 1) confirms the conclusions reached above. Briefly, miniature swards of perennial ryegrass were cut twice weekly at cutting heights of 20 $\mathrm{mm}, 40 \mathrm{~mm}, 80 \mathrm{~mm}, 120 \mathrm{~mm}$ and $160 \mathrm{~mm}$ until tiller population densities were considered to be at equilibrium for the respective cutting heights (excepting the $20 \mathrm{~mm}$ swards), approximately 5 months from sowing. Consistent with the general pattern shown in Figure 1, size/density compensation occurred at a slope steeper than $-3 / 2$ (actually $-2.31 \pm 0.02$ ) for swards cut at $40 \mathrm{~mm}, 80 \mathrm{~mm}$ or $120 \mathrm{~mm}$. The vertical distance from the compensation line thus increased with increasing defoliation intensity below $120 \mathrm{~mm}$ cutting height (Table 1), and this distance was highly correlated $\left(\mathrm{P}=0.004, \mathrm{R}^{2}=0.96\right)$ with productivity over the entire range of cutting heights. By contrast, tiller density was uncorrelated with productivity $\left(\mathrm{P}=0.539, \mathrm{R}^{2}=0.14\right)$.

Table 1 Tiller size $(\mathrm{mg})$, tiller density (tillers $\left./ \mathrm{m}^{*}\right)$, leaf mass $(\mathrm{g} / \mathrm{m})$, herbage production $\left(\mathrm{g} / \mathrm{m}^{2} / \mathrm{day}\right)$ and distance $(\log$, units) from size/density compensation line for perennial ryegrass swards maintained at different cutting heights in a glasshouse experiment.

\begin{tabular}{|c|c|c|c|c|c|c|}
\hline $\begin{array}{l}\text { Cutting } \\
\text { height } \\
\text { (mm) }\end{array}$ & $\begin{array}{l}\text { Tiller } \\
\text { weight } \\
\text { (mg) }\end{array}$ & $\begin{array}{c}\text { Tiller } \\
\text { density } \\
\left(t / m^{2}\right)\end{array}$ & $\begin{array}{c}\text { Leaf } \\
\text { mass } \\
\left(g / m^{2}\right)\end{array}$ & (g & $\begin{array}{l}\text { Herbage } \\
\text { harvested } \\
\left.\mathrm{DM} / \mathrm{m}^{2} / \mathrm{dy}\right)\end{array}$ & $\begin{array}{l}\text { Distance from } \\
\text { from size/density } \\
\text { (log units)' }\end{array}$ \\
\hline 20 & 16. 7 & 6120 & 43 & & 1.02 & -0.79 \\
\hline 40 & 25.4 & 9450 & 90 & & 4. 62 & .0 .16 \\
\hline 80 & 40.2 & 7730 & 114 & & 5.78 & .0 .07 \\
\hline 120 & 52.2 & 6920 & 138 & & 7.01 & 0.00 \\
\hline 160 & 73.6 & 4710 & 127 & & 3.67 & .0 .12 \\
\hline
\end{tabular}

1. Size/density compensation line arbitrarily positioned on the co-ordinates for the $120 \mathrm{~mm}$ cutting height.

Figure 2 Schematic diagram of final tiller size/density status for swards subject to different frequencies of defoliation in winter (points $A$ to $D$ ) and effect ofgrazing (points $A$, to $D$,). A denotes most frequent defoliation, $D$ denotes least frequent

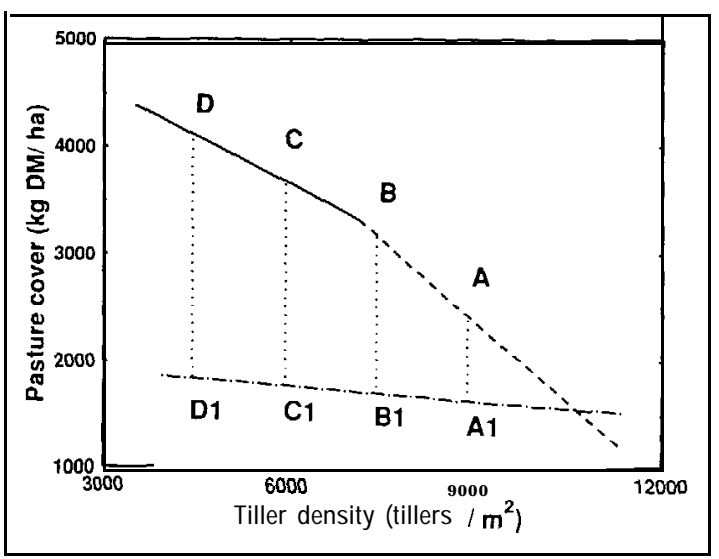


The finding of Parmenter \& Boswell (1983) of decreased pasture growth following longer grazing intervals is also predicted by tiller size/density compensation theory. Swards grazed less frequently over winter would be expected to develop a spread of tiller size/density co-ordinates along a compensation line (Points A to D in Figure 2, compare with Figure 1). Grazing in spring to a common herbage mass (and by implication a similar tiller size) would leave longerspelled swards further from the compensation line (Points A, to D, Figure 2). Although one more formal study failed to find confirmatory evidence (Clark et al. 1995), there are anecdotal reports of lower-than-expected spring production following high winter pasture covers which occur when dairy stock are overwintered in barns or grazed off farm. If real, such effects would also be explained by Figure 2 .

In a more quantitative sense, size/density compensation theory may also be used to compare the status of two or more swards. For example, swards of ryegrass cultivars Wendy (diploid) and Condesa (tetraploid with larger tiller size than Wendy) showed evidence of size/ density compensation (Table 2, extracted from Neuteboom et al. 1988). Clearly, tiller density and tiller size must both be considered, as $\mathrm{X}$ - and $\mathrm{Y}$ - coordinates respectively, in order to compare the tiller density status of these two swards. An approximate' "tiller density correction factor" to take account of average differences in tiller size can be calculated as follows:

Correction factor $=$ antilog, $[2 / 3 * \log ,,($ Tiller size sward $\mathrm{B} /$ Tiller size sward $\mathrm{A}$ )]

or alternatively:

Correction factor $=($ Tiller size sward $\mathrm{B} /$ Tiller size sward $\mathrm{A})^{2 / 3}$

Thus using data in Table 2, Wendy would be expected to maintain a tiller density 1.26 times that of Condesa for a comparable productivity status. However, the observed ratios of tiller density for the two cultivars was 1.42 (Table 2) and 1.44 in field swards (using mean data from Table 1 of Neuteboom et al. 1993). This analysis therefore indicates that Wendy more than compensates for smaller tiller size compared with Condesa, and confirms the view of Neuteboom et al. (1993) that Condesa swards were more open, allowing greater weed ingress than was observed in swards of Wendy.

1. A small correction for change in leaf:non leaf ratio with change in tiller 'size is also required. Typically this correction decreases compensation slope by approximately 0.1 to 0.2 units, partially offsetting the leaf area effect (Matthew et al. 1995a).
Table 2 Tiller size and tiller density for glasshouse swards of ryegrass cultivars Wendy (diploid) and Condesa (tetraploid). Data extracted from results for I OON uncut treatment of Neuteboom et al. (1988).

\begin{tabular}{lcc}
\hline & Wendy & Condesa \\
\hline Tiller weight $(\mathrm{mg})$ & 90 & 127 \\
Tiller density $\left(t / \mathrm{m}^{2}\right)$ & 1851 & 1304 \\
\hline
\end{tabular}

The analogous correction factor to compare expected tiller densities at different levels of pasture cover, using the $-1 / 2$ formulation of the size/density compensation rule is:

Correction factor $=($ Pasture cover sward $\mathrm{B} /$ Pasture cover sward $\mathrm{A})^{2}$

For example, a set stocked sward with pasture cover of $1000 \mathrm{~kg} \mathrm{DM} / \mathrm{ha}$ would need to have a tiller density 4 times that of a similar sward maintained at $2,000 \mathrm{~kg}$ $\mathrm{DM} / \mathrm{ha}$, in order to lie on a common line of slope $-1 / 2$ (implying a comparable productivity status). By contrast, observed slopes steeper than $-1 / 2$ as in Figure $1 \mathrm{~b}$ would generate a less than three-fold increase in tiller density over this same herbage mass range. The take home message is as noted above for glasshouse swards defoliated at $40 \mathrm{~mm}, 80 \mathrm{~mm}$ or $120 \mathrm{~mm}$. For field swards where tiller density gradation arises from difference in defoliation pressure (cf. Table 1), use of both tiller density and pasture cover data to rank swards in terms of their distance from a theoretical compensation line will likely reverse the ranking that would be obtained if uncorrected tiller densities were used instead.

\section{Conclusions}

In order to make sensible use of tiller density data, it is necessary to distinguish between size/density compensation effects and tiller density differences arising from inherent differences in ability of two populations to maintain a given sward leaf area. Such differences might arise from environmental (c.g increased light levels in summer) or genetic (e.g., increased site filling ratio) factors.

Below a certain threshold herbage mass at which tiller density begins to fall below the size/density compensation line, higher tiller densities associated with heavier defoliation pressure are insufficient to compensate for associated loss of leaf area. Swards maintained at lower tiller density and higher herbage mass will be theoretically more productive. The threshold is not well defined in this study and will show seasonal variation, but appears to be in the range from just over 
$2000 \mathrm{~kg} \mathrm{DM} / \mathrm{ha}$ in winter to near $5000 \mathrm{~kg} \mathrm{DM} / \mathrm{ha}$ during reproductive growth in late spring.

When comparing tiller densities of two or more swards, associated differences in tiller size or, alternatively, herbage yield should be taken into account.

\section{REFERENCES}

Anon. 199 1. Fast rotation = Pastures thick with ryegrass, clover; higher solids milk. New Zealand dairy exporter 66(10): 24-27.

Bircham, J.S.; Hodgson, J. 1983. The influence ofsward condition on rates of herbage growth and senescence in mixed swards under continuous stocking management. Grass and forage science 38: 323331.

Brock, J.L.; Hay, R.J.M. 1993. An ecological approach to forage management. Proceedings of the XVII International Grassland Congress: 837-842.

Brougham, R.W. 1956. The rate of growth of shortrotation ryegrass pastures in the late autumn, winter and early spring. New Zealand journal of science and technology A38: 78-87.

Chapman, D.F.; Lemaire, G. 1993. Morphogenetic and structural determinants of plant regrowth after defoliation. Proceedings of the XVII International Grassland Congress: 95- 104.

Clark, D.A.; Carter, W.; Walsh, B.; Clarkson, F.H.; Waugh, CD. 1995. Effect of winter pasture residuals and grazing off on subsequent milk production and pasture performance. Proceedings of the New Zealand Grassland Association 56: 55-59.

Davies, A. 1977. Structure of the grass sward. In Proceedings of an international meeting on animal production from temperate grassland. Ed. B. Gilsenan. pp. 36-44. An Foras Taluntais, Dublin.

Davies, A. 1988. Theregrowth of grass swards. Chapter 3. In The Grass Crop. Eds. Jones, M.B.; Lazenby, A. pp 85-127. Chapman \& Hall, London.
Hutchings, M.J. 1983. Ecology's law in search of a theory. New scientist 98: 765-767.

Langer, R.H.M. 1963. Tillering in herbage grasses. A review article. Herbage abstracts 33; 141-148.

Lonsdale, W.M. 1990. The self-thinning rule: deal or alive? Ecology 71: 1373-1388.

Matthew, C.; Lemaire, G.; Sackville Hamilton, N.R; Hemandez-Garay, A. 1995a. A modified self-thinning equation to describe size/density relationships for defoliated swards. Annals of botany 76: 579-587.

Matthew, C; Matthews, P.N.P.; Hodgson, J. Bluett, S.J. 1995b. Growth of pasture - principles and their application. Dairyfarming annual 47: 122-129.

Neuteboom, J.H.; Lantinga, E.A.; Wind, K. 1988. Tillering characteristics of diploid and tetraploid perennial ryegrass. Proceedings of the 12 th general meeting of the European grassland federation, pp 498-503.

Neuteboom, J.H.; Lantinga, E.A.; Schlepers, H.; t'Mannetje, L. 1993. Swards characteristics of a diploid and a tetraploid cultivar of perennial ryegrass as measured by different sampling techniques. Proceedings of the XVII International Grassland Congress: $362-363$.

Parmenter, G.A.; Boswell, C.C. 1983. Effect of number and timing of winter grazings on winter and spring production. New Zealand journal of experimental agriculture 11: 281-287.

Sackville Hamilton, N.R.; Matthew, C.; Lemaire, G. 1995. Self-thinning: are-evaluation of concepts and status. Annals of botany 76: 569-577.

Weller, D.E. 1987. Self-thinning exponent correlated with allometric measures of plant geometry. Ecology 68: 813-821.

Yoda, K.; Kira, T., Ogawa, H.; Hozumi, H. 1963. Selfthinning in overcrowded pure stands under cultivated and natural conditions. Journal of Osaka City University Institute of Polytechnics, Series D 14: 107-I 29. 